\title{
Influência da renda domiciliar per capita na alocação do tempo dos jovens no Brasil
}

Jaqueline Severino da Costa ${ }^{1}$

Kalinca Léia Becker²

Andressa Rodrigues Pavão ${ }^{3}$

Resumo: O objetivo deste estudo é analisar se políticas públicas para elevar a renda domiciliar per capita das famílias que se encontram no meio rural podem contribuir para elevar a escolaridade do jovem. O método probit bivariado foi utilizado para estimar as probabilidades de os jovens trabalharem ou frequentarem escola. Os resultados encontrados mostraram que a renda domiciliar per capita tem impactos importantes sobre a alocação do tempo do jovem. Jovens de famílias com maior renda tem mais chance frequentar a escola. Jovens de famílias pobres são os que mais precocemente entram no mercado de trabalho, principalmente na área rural. Palavras-chave: alocação do tempo; renda; biprobit.

\section{JEL: J22, D14, C25}

\section{Influence of per capita household income on young people time allocation in Brazil}

\begin{abstract}
This paper aims to analyze if public policies to raise the per capita household income of families who are in rural areas can contribute to increase the young people education. The bivariate probit method was used to estimate the likelihood of young people working or attending school. The results show that the per capita income has important impacts on the young time allocation. Young people from families with higher incomes are more likely to attend school. Young people from poor families are those that come earlier in the labor market, mainly in rural area.
\end{abstract}

Key-words: allocation of the time; income; biprobit.

JEL: J22, D14, C25

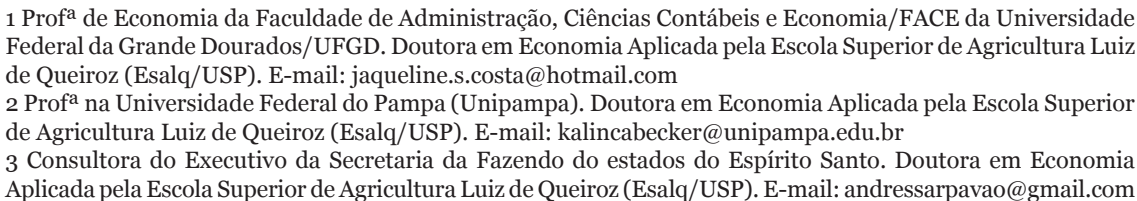




\section{Introdução}

Vários estudos têm enfatizado as mudanças nos processos de alocação do tempo dos jovens entre estudar e trabalhar, no Brasil. Os modelos tradicionais de alocação do tempo se caracterizam pela sequência saída da escola, entrada no mercado de trabalho e saída de casa coincidindo com o casamento e nascimento do primeiro filho.

Embora ainda sejam predominantes, esses modelos estão convivendo com novas trajetórias marcadas, muitas vezes, pela imprevisibilidade no que se refere à transição escola-trabalho. É cada vez mais frequente a combinação de atividades e situações características dos mundos jovem e adulto, resultando em diversas categorias intermediárias no processo de transição para a vida adulta (Hasenbalg, 2003; Wajnman, Leme; 2000; Corseuil et al.,2001; Barros, Mendonça; 1991).

Nos países desenvolvidos, na maioria das vezes, a entrada no mercado de trabalho ocorre após a conclusão da educação formal. A regra a ser cumprida pelos jovens é que façam trajetórias escolares prolongadas e que minimamente terminem a educação compulsória estipulada. No entanto, no Brasil e em outros países da América Latina, essa sequência nem sempre se verifica devido à entrada precoce no mercado de trabalho e à conciliação ou superposição entre escola e trabalho (Hasenbalg, 2003).

O número de jovens brasileiros que não estudam e não trabalham é elevado, conforme pode ser observado na figura 1. Segundo dados da PNAD de 2009, o percentual de jovens que só trabalham é maior entre os que vivem na área rural $(37,6 \%)$ em comparação os que moram na urbana (33,9\%). De maneira contrária, nos centros urbanos há a predominância de jovens que só estudam, $31,2 \%$, em comparação a área rural, 24,6\%.

Vale ressaltar que a quantidade de jovens que não trabalham e não estudam no Brasil é de aproximadamente $19 \%$, sendo muito próximos os valores para quem reside na área rural ou urbana. Isto mostra que grande parte dos jovens que compõe a presente e a futura população economicamente ativa (PEA) do país vive na ociosidade (figura 1).

Tal fenômeno pode ter implicações importantes tanto sociais como econômicos. O fato de o jovem não frequentar a escola pode acarretar em prejuízos ao desenvolvimento do país, uma vez que a educação é apontada como condição necessária. Espera-se que um jovem faça parte do sistema educacional de forma a melhorar sua capacitação para, assim, ter uma maior facilidade para se integrar ao mercado de trabalho. Como uma boa parte dos jovens não faz essa transição da maneira correta, os prejuízos sociais no futuro para esse grupo podem ser severos. 
FIGURA 1 - ALOCAÇÃO DO TEMPO DO JOVEM (IDADE ENTRE 15 E 24 ANOS) ENTRE TRABALHAR E ESTUDAR, SÓ TRABALHAR, SÓ ESTUDAR OU NEM TRABALHAR E NEM ESTUDAR NO BRASIL, 2009.

-Trabalha e estuda 口Só trabalha 日Só estuda GNem trabalha e nem estuda

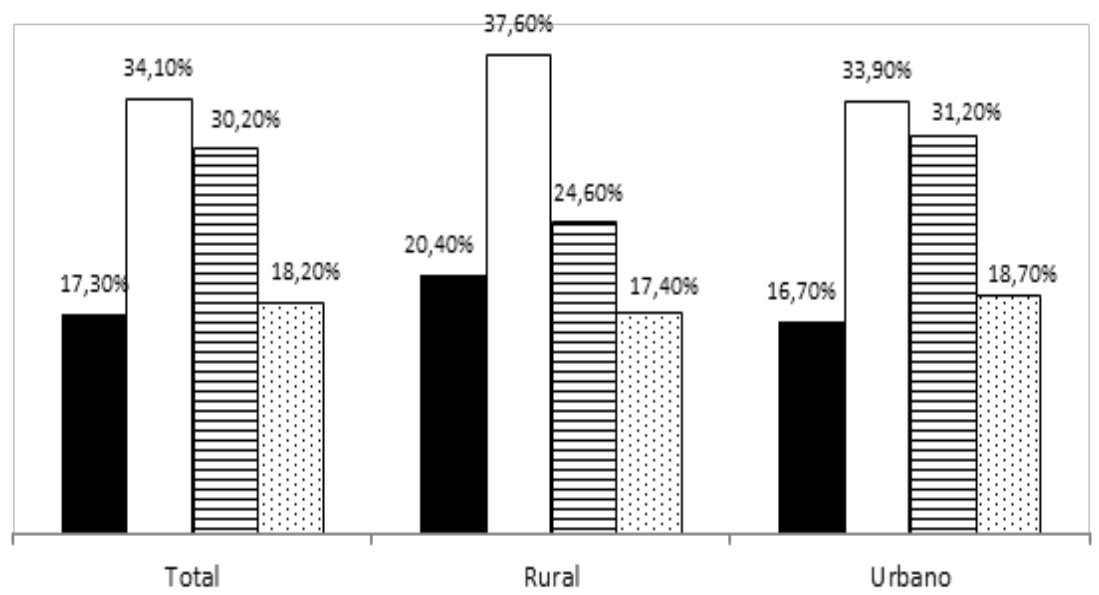

Fonte - PNAD (2009) - IBGE

Os indivíduos avaliam os retornos gerados pelo acúmulo de capital humano no futuro versus os custos de oportunidade do ganho de renda se hoje estivessem atuando na atividade produtiva. De maneira geral, capital humano é medido pelo número de anos de estudos, que por sua vez é resultado do processo de decisão das famílias sobre a alocação do tempo de seus membros mais jovens entre as escolhas de estudar e/ou trabalhar.

Quando a renda familiar é muito baixa, as famílias dependem do trabalho de seus membros mais jovens e, com isso, deixam de investir na educação dos filhos e optam por colocá-los no mercado de trabalho de forma precoce. Consequentemente, correm o risco de perpetuar o ciclo da pobreza de uma geração para a outra. Estas escolhas têm impacto direto sobre os ganhosfamiliares no curto e longo prazo. No curto prazo, a renda do trabalho dos filhos somada ao menor custo de enviá-los a escola são os ganhos obtidos pela família. No longo prazo, os custos da entrada precoce no mercado de trabalho podem ser contabilizados pelos menores salários que os jovens receberão na fase adulta por possuírem baixa escolaridade (Becker, Tomes; 1986).

Nesse sentido, os estudos que tenham como objetivo conhecer o efeito da renda domiciliar sobre a alocação do tempo do jovem são de suma importância, uma vez que este grupo corresponde a uma parte considerável da população economicamente ativa. A proposta de políticas que visam à diminuição da vulnerabilidade social destes jovens vem ganhando destaque, principalmente 
COSTA, J. S.; BECKER, K. L.; PAVÃO, A. R. Influência da renda domiciliar........

quando se considera a população de jovens que residem nas áreas rurais do Brasil, pois muitos deles não têm acesso à escola e desde muito cedo são obrigados a ajudar os pais no cultivo de lavouras ou nos afazeres domésticos, principalmente em regiões em que predominam a agricultura familiar.

Jovens e adolescentes oriundos de classes sociais menos privilegiadas são mais vulneráveis às condições socioeconômicas em que estão inseridos. No intuito de contribuir para a discussão, o presente trabalho tem como objetivo analisar o efeito da renda domiciliar na decisão de alocação do tempo dos jovens (com idade entre 15 e 24 anos) entre trabalhar e estudar, particularmente na parte rural do Brasil. Para a análise será utilizado um modelo probit bivariado, que tem como foco estimar as probabilidades de os jovens trabalharem ou frequentarem escolas em função da variável de interesse, renda domiciliar per capita, além de outras características individuais, familiares e demográficas.

O trabalho está organizado em 5 seções, além desta introdução. Na segunda seção, será realizada uma breve revisão de literatura teórica e empírica dos determinantes da alocação do tempo para balizar a proposta do modelo empírico. Na terceira seção, serão apresentados o banco de dados e os procedimentos econométricos. Na quarta seção serão apresentados os resultados das estimações, bem como as discussões. Por fim serão apresentadas as considerações finais.

\section{Uma breve revisão de literatura}

Em economia, a maioria das pesquisas para explicar a alocação do tempo entre o investimento em capital humano e o mercado de trabalho baseia-se na teoria proposta por Becker (1993). Nesta teoria, as famílias são pequenas unidades que maximizam a utilidade a partir do consumo de bens, de serviços e de lazer, sujeito as restrições de tempo e de renda. Pressupõe-se que o tempo é distribuído entre trabalho, lazer e educação. Mais tempo gasto em uma determinada tarefa significa menos tempo despendido em outra, criando um regime de trocas.

Embora o lazer seja considerado preferível ao trabalho, implica em menos renda para consumir bens de mercado. A educação é vista como um bem de investimento que gera custos presentes, relacionados à quantidade de bens de consumo a que se deve renunciar, e também gera benefícios futuros, obtidos através do ganho adicional de um maior nível de instrução. Com base neste modelo, a decisão familiar tem um papel fundamental na alocação do tempo do jovem.

Vários estudos no Brasil consideram as características familiares como um fator determinante do trabalho, da renda e da educação dos jovens. Barros et 
al. (2001) analisam a escolaridade de pessoas entre 11 e 25 anos e observaram que a disponibilidade de recursos familiares, medida pela renda familiar per capita e pelo nível de escolaridade dos pais, é um fator importante na determinação do desempenho educacional. Já Kassouf (2001) analisou o trabalho infantil e observou que o maior nível de escolaridade dos pais tem o efeito de reduzir a probabilidade de as crianças trabalharem e aumenta a probabilidade de elas estudarem.

No caso agricultura, Ney e Hoffmann (2003) analisaram o efeito da condição socioeconômica da família de origem sobre o rendimento agrícola e observaram que a escolaridade do pai, a escolaridade da mãe e a ocupação do pai quando o filho tinha 15 anos de idade são determinantes importantes da renda do agricultor.

Além das características da família, as características do jovem também podem influenciar a decisão de alocação do tempo. O aumento da idade do jovem pode estar positivamente relacionado à decisão de trabalhar, pois à medida que a idade avança, cresce a inserção dos jovens no mercado de trabalho. Oliveira e Rosa (2006) observaram que a porcentagem de crianças frequentando a escola diminui com o avanço da idade. A partir dos 19 anos, trabalhar se torna a atividade principal dos jovens.

Muitos trabalhos empíricos apontam que características como o sexo e a cor estão relacionadas ao salário e a educação dos indivíduos. No caso da cor, Zucchi e Hoffmann (2004) mostraram que a média de renda dos indivíduos negros é menor do que dos indivíduos brancos e que a educação é um dos principais fatores para explicar este fato. Neste mesmo sentido, Guimarães (2006) observou que o salário do trabalhador negro é 17\% menor que o salário do trabalhador branco e que $70 \%$ desta diferença se refere aos atributos produtivos, como a educação, o setor de trabalho e os aspectos geográficos. Nestes aspectos, os negros se encontram em desvantagem, já que apresentam menor nível de educação, trabalham em setores com menor remuneração e tem maior representatividade nas regiões Norte e Nordeste, que apresentam piores condições de trabalho.

Já no caso do sexo, Kassouf (1998) observou que o rendimento médio das mulheres é 25\% menor que o rendimento dos homens, ao analisar dados de 1989. Porém, quando as características das mulheres são substituídas na equação de salário dos homens, o rendimento estimado das mulheres fica acima do rendimento dos homens. Isso caracteriza uma grande discriminação salarial por gênero no Brasil, conforme a autora.

Scorzafave e Pazello (2007) constataram que em 1998, o salário dos homens era $47,5 \%$ maior que o salário das mulheres, mas esta diferença diminuiu para 21,6\% em 2004. Outra constatação é que muitas mulheres trabalham em regime de tempo parcial. Segundo os autores, este fato, juntamente com a 
COSTA, J. S.; BECKER, K. L.; PAVÃO, A. R. Influência da renda domiciliar........

maior educação das mulheres, tem contribuído para a redução da diferença de salário entre os sexos. Apesar de a diferença no salário dos homens e mulheres estar diminuindo, o salário das mulheres ainda é menor, o que talvez seja um incentivo para que invistam mais tempo estudando.

\subsection{A modelo empírico}

\subsubsection{Base de dados}

A amostra utilizada na presente pesquisa tem como base os dados da Pesquisa Nacional por Amostra de Domicílio (PNAD) de 2009, do Instituto Brasileiro de Geografia e Estatística (IBGE) e conta com 43.069 jovens brasileiros com idade entre 15 e 24 anos.

A PNAD é realizada anualmente e cobre todo o território nacional fornecendo informação sobre as características individuais e familiares, trabalho, renda e educação. Como o foco do estudo é a área rural do Brasil, a amostra será dividida de modo a diferenciar os jovens que residem na área rural dos que residem na área urbana. Assim, além de verificar o efeito da renda domiciliar per capita sobre a alocação do tempo do jovem que reside na área rural, estes resultados serão comparados aos resultados da área urbana. Para a área rural a análise irá considerar 6.689 jovens, enquanto que a área urbana contará com 36.380 jovens.

As decisões entre estudar ou trabalhar serão analisadas considerando a renda domiciliar per capita (excluindo a renda do próprio jovem), variável de interesse, além das características individuais e demográficas. Como variáveis individuais serão consideradas idade, sexo (1 binário se o jovem é do sexo masculino, zero caso contrário) e raça (1 caso o jovem seja não branco e zero caso contrário). A variável familiar considerada será, além de a renda domiciliar per capita, a escolaridade do chefe da família. Além disso, serão consideradas as cinco regiões geográficas, com a inclusão de cinco binárias para diferenciar as regiões. Como serão utilizadas variáveis com base nas características familiares, serão considerados apenas os indivíduos na condição de filho.

\subsubsection{Procedimento econométrico}

Por demandarem alocação do tempo, a decisão do jovem entre trabalhar ou estudar é tomada simultaneamente, de modo que estas atividades são consideradas interdependentes e, nesta fase da vida do indivíduo, passam a concorrer entre si.

Neste caso, estimativas consistentes podem ser obtidas através de um modelo probit bivariado, que permite a existência de correlação entre os erros 
das duas equações, e permite testar também se a estimação conjunta tem significativamente maior poder de explicação que a utilização de uma equação univariada para cada decisão. Portanto, pode-se analisar os determinantes da alocação do tempo entre estudar e trabalhar dos adolescentes e jovens no Brasil rural por meio das equações (1) e (2) a seguir:

$$
\begin{gathered}
L_{i t}^{*}=\alpha_{0}+\alpha_{1} E S C O L_{-} C H E F E_{i t}+\alpha_{2} C_{\text {COR }}+\alpha_{3} I D A D E_{i t}+ \\
\alpha_{4} R D P C_{i t}+\alpha_{5} S_{E X O_{i t}}+\alpha_{6} R_{E G I A O}+\varepsilon_{i t}
\end{gathered}
$$

Em que, $L_{i t}=1$ se o jovem trabalha e $L_{i t}=0$ caso contrário.

$$
\begin{gathered}
E_{i t}^{*}=\beta_{0}+\beta_{1} E S C O L_{-} C H E F E_{i t}+\beta_{2} C O R_{i t}+\beta_{3} I D A D E_{i t}+ \\
\beta_{4} R D P_{i t}+\beta_{5} S E X O_{i t}+\beta_{6} R E G I A O_{i t}+v_{i t}
\end{gathered}
$$

Em que, $E_{i t}=1$ se o jovem trabalha e $E_{i t}=0$ caso contrário.

Em que $E S C O L \_C H E F E_{i t}$ refere-se a escolaridade do chefe da família, $C O R_{i t}$ refere-se a cor ou raça do indivíduo, $I D A D E_{t t}$ representa a idade do jovem, $R D P C_{i t}$ representa a renda domiciliar per capita (excluindo a renda do jovem); $S E X O_{i t}$ representa o gênero do jovem e $R E G I A O_{i t}$ representa a região geográfica em que ojovem reside. Para estimativas do probit bivariado cabe considerar a seguintes hipóteses: $E(\varepsilon i t)=E(\nu i t)=0, \operatorname{Var}(\varepsilon i t)=\operatorname{Var}(\nu i t)=1, \operatorname{Cov}(\varepsilon i t, \nu i t)=\rho$ por fim $(\varepsilon i t, v i t) \sim B V N(0,001, \rho)$.

\subsubsection{Análise preliminar dos dados}

A Tabela 1 apresenta a média, o desvio padrão, o valor máximo e o mínimo das variáveis utilizadas para analisar a escolha do jovem entre trabalhar e estudar. Em média, a renda domiciliar per capita (excluindo a renda do próprio jovem) é duas vezes maior para os que residem na área urbana, se comparada aos que residem na área rural. A participação dos jovens que trabalham e estudam é maior na área rural. Já a participação dos jovens que não trabalham e não estudam é maior na área urbana.

Na tabela 2 estão as médias das variáveis selecionadas para estimar as probabilidades de os jovens trabalharem ou frequentarem escola, condicionadas a alocação do tempo do jovem. Observamos que na área urbana, a maior média de renda domiciliar per capita (RDPC) é a dos jovens que estudam e trabalham. A média de idade e de escolaridade do chefe da família destes jovens é bastante próxima das respectivas médias dos jovens que só estudam. 
COSTA, J. S.; BECKER, K. L.; PAVÃO, A. R. Influência da renda domiciliar........

TABELA 1 - MÉDIA, DESVIO-PADRÃO, MÍNIMO E MÁXIMO PARA AS VARIÁVEIS UTILIZADAS NAS ESTIMAÇÕES PARA ÁREA RURAL E URBANA DO BRASIL, 2009.

\begin{tabular}{|c|c|c|c|c|}
\hline \multirow[b]{2}{*}{ Variáveis } & \multicolumn{2}{|c|}{ Rural } & \multicolumn{2}{|c|}{ Urbano } \\
\hline & Média & $\begin{array}{l}\text { Mínimo/ } \\
\text { máximo }\end{array}$ & Média & $\begin{array}{l}\text { Mínimo/ } \\
\text { máximo }\end{array}$ \\
\hline \multirow{2}{*}{$\begin{array}{l}\text { Renda domiciliar } \\
\text { per capita }\end{array}$} & $\mathrm{R} \$ 242,12$ & $\mathrm{R} \$ 4,40$ & $\mathrm{R} \$ 517,42$ & $\mathrm{R} \$ 3,33$ \\
\hline & $(\mathrm{R} \$ 303,06)$ & $\mathrm{R} \$ 8.116,25$ & $(\mathrm{R} \$ 813,95)$ & $\mathrm{R} \$ 56.900,00$ \\
\hline \multirow[t]{2}{*}{ Trabalha } & 37,7 & $\mathrm{O}$ & 32,9 & o \\
\hline & $(48,4)$ & 1 & $(46,9)$ & 1 \\
\hline \multirow[t]{2}{*}{ Estuda } & 25,2 & o & 32,1 & o \\
\hline & $(43,4)$ & 1 & $(46,7)$ & 1 \\
\hline \multirow[t]{2}{*}{ Trabalha e estuda } & 21,0 & o & 16,8 & o \\
\hline & $(40,6)$ & 1 & $(37,4)$ & 1 \\
\hline \multirow{2}{*}{$\begin{array}{l}\text { Nem trabalha e nem } \\
\text { estuda }\end{array}$} & 16,2 & o & 18,1 & o \\
\hline & $(36,8)$ & 1 & $(38,5)$ & 1 \\
\hline \multirow[t]{2}{*}{ Idade do jovem } & 18,3 & 15 & 18,8 & 15 \\
\hline & $(2,6)$ & 24 & $(2,7)$ & 24 \\
\hline \multirow{2}{*}{$\begin{array}{l}\text { Jovem de cor/raça } \\
\text { não-branca }\end{array}$} & 73,6 & o & 65,2 & o \\
\hline & $(44,0)$ & 1 & $(47,6)$ & 1 \\
\hline \multirow{2}{*}{$\begin{array}{l}\text { Jovem do sexo mas- } \\
\text { culino }\end{array}$} & 61,1 & o & 54,7 & o \\
\hline & $(49,2)$ & 1 & $(48,0)$ & 1 \\
\hline \multirow{2}{*}{$\begin{array}{l}\text { Escolaridade do che- } \\
\text { fe da família }\end{array}$} & 3,9 & o & 7,6 & o \\
\hline & $(3,8)$ & 16 & $(4,3)$ & 16 \\
\hline \multirow[t]{2}{*}{ Sul } & 12,9 & o & 14,4 & o \\
\hline & $(33,5)$ & 1 & $(35,1)$ & 1 \\
\hline \multirow[t]{2}{*}{ Sudeste } & 13,7 & o & 28,6 & o \\
\hline & $(34,4)$ & 1 & $(45,2)$ & 1 \\
\hline \multirow[t]{2}{*}{ Norte } & 18,4 & o & 13,9 & o \\
\hline & $(38,8)$ & 1 & $(34,6)$ & 1 \\
\hline \multirow[t]{2}{*}{ Nordeste } & 47,8 & o & 31,1 & o \\
\hline & $(49,9)$ & 1 & $(46,3)$ & 1 \\
\hline \multirow[t]{2}{*}{ Centro-Oeste } & 6,9 & o & 11,8 & o \\
\hline & $(25,4)$ & 1 & $(32,3)$ & 1 \\
\hline
\end{tabular}

Fonte: Elaborada com base nos dados da PNAD (IBGE, 2009) 
COSTA, J. S.; BECKER, K. L.; PAVÃO, A. R. Influência da renda domiciliar........

Já na área rural, a maior média de RDPC é dos jovens que só estudam, que também tem a maior média de escolaridade do chefe, aproximadamente 4 anos de estudo. Pode-se observar ainda, na tabela 1, que a escolaridade do chefe da família da área rural é, em média, duas vezes menor se comparada aos chefes que residem na área urbana.

TABELA 2 - MÉDIA DAS VARIÁVEIS SELECIONADAS, CONDICIONAL A ALOCAÇÃO DO TEMPO, PARA ÁREA RURAL E URBANA DO BRASIL, 2009.

\begin{tabular}{lrrrrrr}
\hline & RDPC & Idade & Cor & Sexo & \multicolumn{1}{c}{$\begin{array}{c}\text { Esc.do } \\
\text { chefe }\end{array}$} \\
\hline Urbano & & & & & \\
\hline Não trabalha e não & 374,45 & 20,43 & 0,619 & 0,549 & 6,66 \\
estuda & $(9,317)$ & $(0,046)$ & $(0,010)$ & $(0,010)$ & $(0,089)$ \\
Estuda & 468,83 & 18,22 & 0,562 & 0,487 & 7,62 \\
& $(11,658)$ & $(0,048)$ & $(0,010)$ & $(0,010)$ & $(0,092)$ \\
Trabalha & 424,37 & 20,83 & 0,550 & 0,663 & 6,29 \\
Trabalha e estuda & $(6,453)$ & $(0,023)$ & $(0,005)$ & $(0,005)$ & $(0,044)$ \\
& 598,15 & 18,87 & 0,499 & 0,562 & 7,75 \\
Rural & $(12,484)$ & $(0,032)$ & $(0,006)$ & $(0,006)$ & $(0,054)$ \\
\hline Não trabalha e não & 197,80 & 19,87 & 0,669 & 0,591 & 3,45 \\
estuda & $(12,323)$ & $(0,180)$ & $(0,038)$ & $(0,040)$ & $(0,294)$ \\
Estuda & 249,60 & 17,84 & 0,685 & 0,470 & 4,01 \\
Trabalha & $(25,890)$ & $(0,158)$ & $(0,036)$ & $(0,039)$ & $(0,284)$ \\
& 228,00 & 20,23 & 0,617 & 0,802 & 2,69 \\
& $(5,628)$ & $(0,053)$ & $(0,011)$ & $(0,009)$ & $(0,074)$ \\
\hline & 221,90 & 17,62 & 0,663 & 0,712 & 3,17 \\
& $(8,555)$ & $(0,055)$ & $(0,011)$ & $(0,011)$ & $(0,085)$ \\
\hline
\end{tabular}

Fonte: Elaborada com base nos dados da PNAD (IBGE, 2009). Valores entre parênteses representam o desvio-padrão.

As características pessoais utilizadas nas estimativas são compostas por idade, sexo e cor. A variável idade corresponde à idade do jovem, sendo que esta pode variar de 15 a 24 anos. Em média a idade dos jovens, tanto da área rural quanto área urbana, é 18 anos (tabela 1). Observamos também que as médias de idade são menores para os jovens que só estudam ou estudam e trabalham, em torno de 18 anos, em comparação aos jovens que só trabalham ou não trabalham e não estudam, em torno de 20 anos em ambas as áreas (tabela 2). 
COSTA, J. S.; BECKER, K. L.; PAVÃO, A. R. Influência da renda domiciliar........

Através da figura 2, que considera apenas a amostra de jovens que só trabalham ou só estudam, observamos que trabalhar torna-se a atividade principal dos jovens na área urbana entre os 17 e 18 anos. No caso da área rural, trabalhar é a atividade principal para a maioria dos jovens.

Os jovens que se autodeclaram de cor ou raça não branca são maioria (tabela 1). Com relação ao sexo, pode-se observar que a maior parte dos jovens é do sexo masculino, principalmente na área rural (tabela 1). É interessante observar que, nesta área, a proporção de homens que trabalham é bastante elevada, $80 \%$ da amostra que só trabalha e $71 \%$ da amostra que estuda e trabalha (tabela 2). Isso pode ser devido à prevalência da cultura do casamento ainda na juventude, onde o homem é o provedor da família e a mulher trabalha no lar.

\section{Resultados e discussão}

Os resultados das estimativas referentes às probabilidades de o jovem trabalhar ou estudar na área rural brasileira, comparados à área urbana são apresentados na Tabela 3. Além destas estimativas, foram feitas estimativas com base na amostra total.

A correlação entre os termos distúrbios das duas equações, jovens que trabalham e jovens que estudam, é mensurada pelo coeficiente de correlação rho $(\rho)$. O valor encontrado é negativo e estatisticamente significante. Este resultado demonstra que trabalhar e estudar são decisões que são tomadas simultaneamente, ou seja, estudar e trabalhar são atividades concorrentes na decisão de alocação de tempo dos jovens. Por isso, as equações de trabalho e frequência à escola devem ser estimadas conjuntamente em um modelo probit bivariado (biprobit) ao invés de equações probit separadas.

Segundo Becker e Tomes (1986) a renda familiar é fator determinante para a alocação do tempo do jovem, uma vez que pode influenciar a entrada precoce no mercado de trabalho. Os resultados encontrados mostram que a renda per capita do domicílio (excluindo a renda do próprio jovem) é relevante para alocação do tempo do jovem, principalmente para os jovens da área rural do Brasil.

Pode-se observar que, de maneira geral, à medida que a renda domiciliar per capita aumenta, as chances de o jovem trabalhar diminuem significativamente. Estes resultados estão de acordo com os resultados encontrados por Oliveira e Rosa (2006) de que quanto maior a renda, menor a chance de um jovem trabalhar. 
FIGURA 2 - PROPORÇÃO DE JOVENS QUE SÓ TRABALHAM OU SÓ ESTUDAM, POR IDADE, NO BRASIL, 2009.

\section{Urbano}

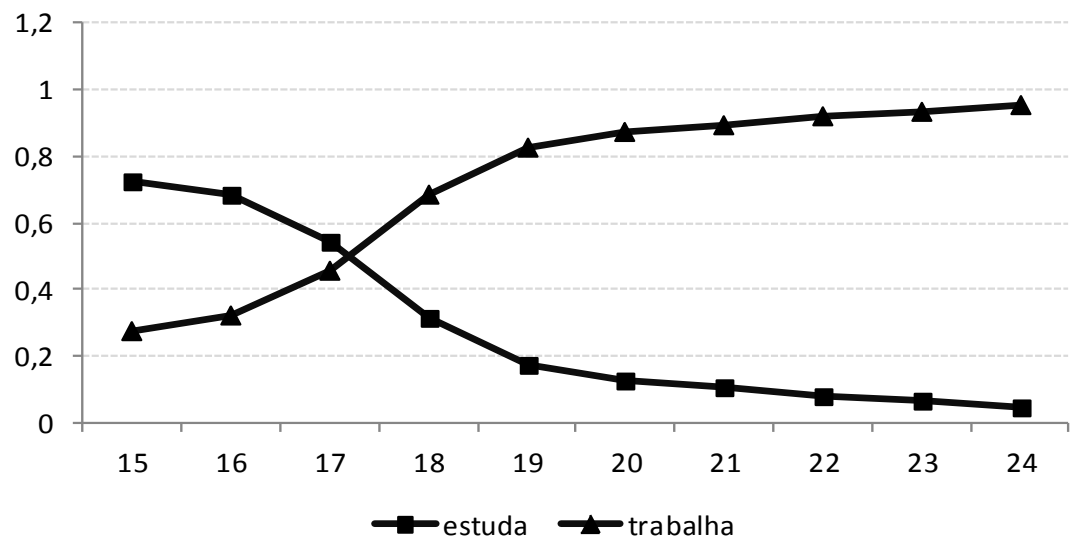

Rural

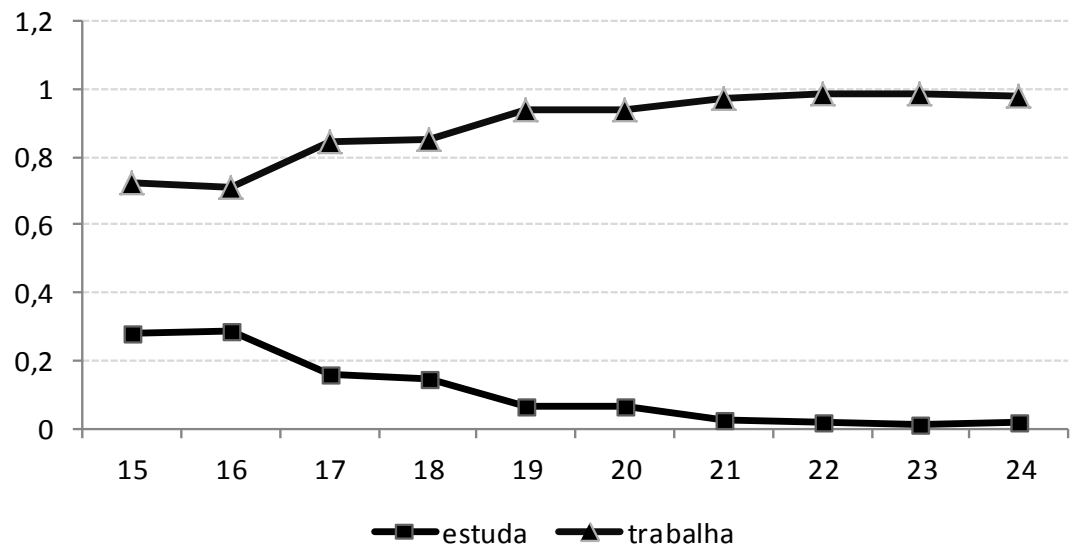

Fonte - PNAD (2009) - IBGE 
Porém, o coeficiente estimado da renda domiciliar per capita dos jovens que residem na área rural é menor se comparado ao coeficiente estimado daqueles que residem na área urbana. Isso demonstra que, mesmo com um aumento na renda na área rural, a possibilidade de os jovens deixarem de trabalhar é menor se comparados à área urbana. Isso é uma evidência de que a renda do jovem que reside na área rural é importante para a família, o que pode ser devido à agricultura familiar onde, muitas vezes, os jovens ajudam os pais no trabalho.

Com relação à frequência escolar, pode-se observar que a renda domiciliar per capita tem importante efeito tanto para os jovens que residem na área urbana quanto para aqueles que residem na área rural. Assim, quanto maior a renda domiciliar, maior a possibilidade de os jovens frequentarem a escola, porém o efeito dessa variável é menor para os jovens que residem na área rural se comparado ao da área urbana. Mesmo assim, não se pode deixar de considerar que a melhora na renda domiciliar na área rural eleva as chances de os jovens frequentarem a escola, mesmo apontando para a necessidade de estes jovens ajudarem os pais no trabalho rural.

Os resultados da primeira equação mostram que o coeficiente da variável idade é positivo, conforme o esperado, ou seja, à medida que a idade do jovem aumenta as chances de o jovem trabalhar também aumentam. Pode-se observar que este resultado é semelhante tanto para os que residem na área urbana quanto na área rural.

Inversamente, com o aumento na idade dos jovens, a tendência é que a frequência escolar diminua, tanto para os jovens que residem na área urbana quanto rural, porém a frequência cai menos para os jovens da área rural. Esse resultado pode ser também devido ao fato de que muitos jovens que residem na área rural fazem parte da agricultura familiar, sendo que muitas vezes residem no local de trabalho.

Com relação à cor, os resultados divergem para os jovens que residem nas áreas rural e urbana. Para os jovens que residem na área rural, as chances de os jovens não-brancos encontrarem trabalho são negativas, porém não significativas. Diferentemente do que ocorre na área urbana, em que as chances de não-brancos encontrarem trabalho são positivas. 
TABELA 3 - COEFICIENTES ESTIMADOS E P-VALORES PARA O MODELO PROBIT BIVARIADO

\begin{tabular}{lcccc}
\hline Variáveis & Urbano+Rural & Urbano & Rural \\
\hline Equação (1) - Jovem trabalha & \multicolumn{3}{c}{} \\
\hline Log renda domiciliar per capita & $\begin{array}{c}-0,1416 \\
(0,000)^{*}\end{array}$ & $\begin{array}{c}-0,1550 \\
(0,000)^{*}\end{array}$ & $\begin{array}{c}-0,0599 \\
(0,007)^{*}\end{array}$ \\
Idade do jovem & 0,2507 & 0,2508 & 0,2560 \\
& $(0,000)^{*}$ & $(0,000)^{*}$ & $(0,000)^{*}$ \\
Jovem não-branco & 0,0151 & 0,0315 & $-0,0563$ \\
& $(0,336)$ & $(0,071)^{* * *}$ & $(0,187)$ \\
Jovem do sexo masculino & 0,4437 & 0,3816 & 0,7900 \\
& $(0,000)^{*}$ & $(0,000)^{*}$ & $(0,000)^{*}$ \\
Escolaridade do chefe da família & $-0,0396$ & $-0,0355$ & $-0,0444$ \\
Sul & $(0,000)^{*}$ & $(0,000)^{*}$ & $(0,000)^{*}$ \\
& 0,0834 & 0,0528 & 0,2033 \\
Norte & $(0,000)^{*}$ & $(0,032)^{* *}$ & $(0,003)^{*}$ \\
& $-0,3333$ & $-0,3626$ & $-0,3047$ \\
Nordeste & $(0,000)^{*}$ & $(0,000)^{*}$ & $(0,000)^{*}$ \\
Centro-Oeste & $-0,3760$ & $-0,3775$ & $-0,4224$ \\
& $(0,000)^{*}$ & $(0,000)^{*}$ & $(0,000)^{*}$ \\
& $-0,0632$ & $-0,0486$ & $-0,2219$ \\
& $(0,015)^{* *}$ & $(0,074)^{* * *}$ & $(0,010)^{* *}$ \\
& $-4,5478$ & $-4,4814$ & $-5,1439$ \\
& $(0,000)^{*}$ & $(0,000)^{*}$ & $(0,000)^{*}$ \\
\hline
\end{tabular}

Fonte: Elaborada com base nos dados da PNAD (IBGE, 2009)

Nota: ${ }^{* * *},{ }^{* *} \mathrm{e}$ * denotam, respectivamente, significância de 10\%, 5\% e 1\% e ns denota não significativo. 
COSTA, J. S.; BECKER, K. L.; PAVÃO, A. R. Influência da renda domiciliar.......

TABELA 3 - COEFICIENTES ESTIMADOS E P-VALORES PARA O MODELO PROBIT BIVARIADO (Continuação)

\begin{tabular}{lccc}
\hline Equação (2) - Jovem estuda & & & \\
\hline Log renda domiciliar per capita & 0,01602 & 0,1632 & 0,1123 \\
& $(0,000)^{*}$ & $(0,000)^{*}$ & $(0,000)^{*}$ \\
Idade do jovem & $-0,2786$ & $-0,2863$ & $-0,2422$ \\
& $(0,000)^{*}$ & $(0,000)^{*}$ & $(0,000)^{*}$ \\
Jovem não-branco & $-0,3774$ & $-0,0603$ & 0,0367 \\
& $(0,005)^{*}$ & $(0,000)^{*}$ & $(0,374) \mathrm{ns}$ \\
Jovem do sexo masculino & $-0,3774$ & $-0,2958$ & $-0,8127$ \\
& $(0,000)^{*}$ & $(0,000)^{*}$ & $(0,000)^{*}$ \\
Escolaridade do chefe da família & 0,0412 & 0,0368 & 0,0378 \\
Sul & $(0,000)^{*}$ & $(0,000)^{*}$ & $(0,000)^{*}$ \\
& $-0,2317$ & $-0,2128$ & $-0,2729$ \\
Norte & $(0,000)^{*}$ & $(0,000)^{*}$ & $(0,000)^{*}$ \\
Número de observações & 0,2706 & 0,3245 & 0,1774 \\
Nordeste & $(0,000)^{*}$ & $(0,000)^{*}$ & $(0,006)^{*}$ \\
Centro-Oeste & 0,2572 & 0,2842 & 0,2088 \\
& $(0,000)^{*}$ & $(0,000)^{*}$ & $(0,000)^{*}$ \\
& 0,0416 & 0,0289 & 0,2166 \\
& $(0,088)^{* * *}$ & $(0,261) \mathrm{ns}$ & $(0,008)^{*}$ \\
& 3,8253 & 3,9590 & 3,5145 \\
& $(0,000)^{*}$ & $(0,000)^{*}$ & $(0,000)^{*}$ \\
& 43.066 & 36.377 & 6.689 \\
& & & $-0,9777$ \\
& $(0,000)^{*}$ & $(0,000)^{*}$ & $(0,000)^{*}$ \\
\hline
\end{tabular}

Fonte: Elaborada com base nos dados da PNAD (IBGE, 2009)

Nota: ***, ** $\mathrm{e}^{*}$ denotam, respectivamente, significância de 10\%, 5\% e 1\% e ns denota não significativo.

A busca por emprego do jovem não-branco talvez ocorra em função do menor estoque de recursos dessas famílias, em especial negros e pardos, devido a herança cultural que se traduz em menor educação e menores salários (Zucchi e Hoffmann, 2004, Guimarães, 2006).

Com relação à frequência escolar, vale ressaltar um resultado interessante, jovens não-brancos que residem na área rural tem mais chances de frequentar escola do que os jovens não-brancos que residem na área urbana. Talvez isso 
ocorra porque na área urbana, as chances de um jovem não-branco encontrar emprego são positivas e significativas, diferentemente da área rural.

Jovens do sexo masculino que residem na área rural ou urbana têm maiores possibilidades de começarem a trabalhar do que jovens do sexo feminino. Contudo, ao comparar os jovens do sexo masculino que residem na área rural aos jovens da área urbana, percebe-se que as chances são muito maiores para os jovens da área rural. Com relação à frequência escolar, pode-se observar que os jovens do sexo masculino, tanto da área urbana quanto da área rural, têm menores chances de frequentar escolas do que jovens do sexo feminino. De forma comparativa, observa-se que os jovens do sexo masculino que residem na área rural têm menos chances de frequentar escola do que os jovens do sexo masculino da área urbana. Resultados semelhantes foram encontrados por Oliveira e Rosa (2006) de que indivíduos do sexo masculino têm maior possibilidade de trabalhar e menores chances de estudar.

Isso pode ser devido ao fato de as mulheres terem menores incentivos no mercado de trabalho já que, muitas vezes, o salário é inferior ao salário dos homens mesmo com as mesmas características produtivas (Kassouf, 1998; Barros et al., 1997; Arauújo e Ribeiro, 2002; Soares, 2000; Giuberti e Menezes Filho, 2005; Scorzafave e Pazello, 2007). Na área rural, é possível que este fenômeno seja mais evidente em função de prevalecer mais fortemente a cultura da inserção precoce do homem no mercado de trabalho.

A escolaridade do chefe da família tem efeito negativo sobre o trabalho dos jovens, conforme esperado, ou seja, à medida que a escolaridade do chefe da família aumenta, reduz as chances de os jovens trabalharem. A queda é maior para os jovens que residem na área rural se comparados aos jovens da área urbana.

Quando se analisa a frequência escolar, percebe-se que quanto maior a escolaridade do chefe, maiores as chances de os jovens irem para a escola, isso ocorre tanto para os que residem na área rural quanto na área urbana. Vale ressaltar que, comparativamente, as chances são maiores para os que residem na área rural do que na área urbana. Estes resultados estão de acordo com os encontrados por Oliveira e Rosa (2006) para o Ceará. Segundo os autores, quanto maior a escolaridade do chefe, maiores as chances de os jovens frequentarem escola e menores as chances de os jovens trabalharem. Segundo Ferreira e Veloso (2003), que analisam a mobilidade intergeracional da educação no Brasil, as chances, por exemplo, de o filho de um analfabeto continuar analfabeto é extremamente alta. Portanto, a escolaridade do chefe é fator determinante para a escolaridade do filho. Checci e Flabbi (2007), fazendo um estudo para Itália, também encontram resultados bastante semelhantes ao estimados no presente estudo. 
Existe diferença entre o trabalho dos jovens que residem nas regiões brasileiras. Os jovens que residem na região Sul têm maiores chances de trabalhar se comparados aos jovens da região Sudeste, tomada como base. Vale ressaltar que os jovens que residem na área rural da região Sul tem maior probabilidade de trabalhar se comparadas aos jovens que residem na área urbana. Isso se deve a força da agricultura familiar na região Sul. Nas demais regiões, (Norte, Nordeste e Centro-Oeste) as probabilidades de trabalhar dos jovens são menores se comparadas à região Sudeste.

Com relação à frequência escolar, percebe-se que os jovens situados na área rural da região Sul têm menores chances de frequentarem escolas se comparados à região base Sudeste. Muitos optam por trabalhar ao invés de estudar. Porém, para as demais regiões, tomando a região Sudeste como base, os jovens têm maiores chances de frequentarem escola.

\section{Considerações finais}

Ao analisar o efeito da renda domiciliar per capita sobre a alocação do tempo do jovem no Brasil rural, nota-se que políticas públicas na área rural fazemse necessárias para reduzir as desigualdades observadas entre o rural e o urbano. A análise foi realizada a partir dos dados da PNAD de 2009, excluindo a renda do jovem na variável renda domiciliar per capita, e foi utilizado o método probit bivariado para estimar a probabilidade de o jovem trabalhar ou frequentar a escola.

A partir dos resultados, pode-se observar que a renda domiciliar per capita tem impactos importantes sobre a alocação do tempo do jovem. Famílias com maiores rendas elevam as chances de os jovens que residem na área rural frequentarem escolas e diminuem a sua inserção precoce no mercado de trabalho. Já os jovens de famílias pobres são os que mais precocemente entram no mercado de trabalho. Os resultados encontrados justificam a necessidade de intensificar as políticas públicas de melhoria de renda e educação na área rural, em um nível proporcionalmente superior ao observado na área urbana, de forma a reduzir as desigualdades regionais entre rural e urbano que ainda predominam.

Com relação às demais variáveis, pode-se observar que à medida que a idade do jovem aumenta, reduz-se a probabilidade deste jovem estudar e aumenta a probabilidade deste jovem trabalhar, principalmente na área rural. Assim, quanto mais jovem o indivíduo entra no mercado de trabalho, menor será seu salário no futuro, pois começar trabalhar muito cedo retira os jovens da escola, que por sua vez limita a acessão destes jovens a oportunidades de emprego que exigem maiores qualificações e que oferecem salários maiores, mantendo os jovens dentro de um ciclo de pobreza. 
A variável gênero também foi importante, uma vez que jovens do sexo masculino apresentam maior probabilidade de trabalhar e menor propensão a frequência escolar. A escolaridade dos pais ou do chefe da família reduz a probabilidade de os jovens trabalharem e aumenta as chances dos filhos frequentarem escolas. A cor ou raça dos jovens não tem efeito sobre a possibilidade de os jovens da área rural trabalharem, porém estes jovens têm mais chances de frequentar escola do que os jovens não-brancos que residem na área urbana.

Os resultados apresentados no presente ensaio apontam para a elaboração de políticas mais eficazes do combate ao trabalho precoce, particularmente no campo, de modo a criar melhores condições de renda para a família e intensificar a qualificação profissional destes jovens. Com isso é possível quebrar o ciclo inter-geracional da pobreza, permitindo melhores ganhos de rendas e posições melhores no mercado de trabalho no futuro.

\section{Referências bibliográficas}

Araújo, F. V.; Ribeiro, E.P. (2002). "Diferenciais de salários por gênero no Brasil: uma análise regional." Revista Econômica do Nordeste, vol. 33 (2).

Barros, R. P. de, Machado, F., Mendonça, R. (1997). A desigualdade da pobreza: estratégias ocupacionais e diferenciais por gênero. Texto para Discussão, n. 453.

Barros, R. P.; Mendonça, R. (1991). "Infância e adolescência no Brasil: as conseqüências da pobreza diferenciada por gênero, faixa etária e região de residência." Pesquisa e Planejamento Econômico, vol. 21 (2); p. 355-376.

Barros, R. P.; Mendonca, R.; Santos, D.D.; Quintais, G. (2001).Determinantes do desempenho educacional no Brasil. Texto para Discussão, n. 834.

Becker, G. (1993). Human Capital: A Theoretical and Empirical Analysis, with Special Reference to Education. Chicago, University of Chicago Press 3rd ed.

Becker, G.; Tomes, N. (1986). "Human Capital and the Rise and Fall of Families". Journal of Labor Economics, vol. 4(3), p. S1-39.

Checchi, D. Flabbi L. (2007). "Intergenerational Mobility and Schooling Decisions in Germany and Italy: the Impact of Secondary School Tracks". Working Papers 07-07-08.

Corseuil, C. H.; Santos, D. D.; Foguel, M. (2001). "Decisões críticas em idades críticas: a escolha dos jovens entre estudo e trabalho no Brasil e em outros países da América Latina”.Texto para discussão, n. 797.

Ferreira, S.; Veloso, F. (2003). Do borrowing constraints decrease intergenerational mobility? Evidence from Brazil. Artigo apresentado na XXV Semana Brasileira de Econometria, 2003 (Technical Report).

Giuberti, A. \& Menezes-Filho, N. (2005). "Discriminação dos rendimentos por gênero: uma comparação entre o Brasil e os Estados Unidos". Economia Aplicada, 
COSTA, J. S.; BECKER, K. L.; PAVÃO, A. R. Influência da renda domiciliar.......

vol. 9(3); p. 369-383.

Guimarães, R. O. (2006). "Desigualdade salarial entre negros e brancos no Brasil”. Econômica, vol.8 (2); p. 227-25.

Hasenbalg, C. "A transição da escola ao mercado de trabalho". In: HASENBALG, C.; SILVA, N. V. Origens e destinos: desigualdades sociais ao longo da vida. Rio de Janeiro: Topbooks, 2003.

IBGE. Pesquisa Nacional por Amostra de Domicúlio 2009 - documentação dos microdados da amostra. Rio de Janeiro.

Kassouf, A. L. (1998). "Wage gender discrimination and segmentation in the Brazilian labor market”. Brazilian Journal of Applied Economics, vol. 2(2); p. 243-269.

Kassouf, A. L. (2001). “Trabalho Infantil”. In: LISBOA, M.; MENEZES-FILHO, N. A. Microeconomia e Sociedade no Brasil, Rio de Janeiro.

Leme, M. C. E wajnmam, S.. (2000) A alocação de do tempo dos adolescentes brasileiros entre o trabalho e a escola. Anais do Encontro Nacional da Associação Brasileira de Estudos Populacionais.

Ney, M. G. Hoffmann, R. (2003). "Origem familiar e desigualdade de renda na agricultura”. Pesquisa e Planejamento Econômico, vol. 33 (3).

Oliveira, J. L. Rosa, A.L.T. (2006). "Uma análise dos determinantes da alocação de tempo dos jovens cearenses entre estudar e trabalhar". Texto para discussão, n. 35 .

Scorzafave, L.G.; Pazello, E.T. (2007). "Using normalized equations to solve the indetermination problem in the Oaxaca-blinder decomposition: an application to the gender wage gap in Brazil”. Revista Brasileira de economia, vol. 61 (4), p. 535-548.

Soares, S. S. D. (2000). “O perfil da discriminação no mercado de trabalho - homens negros, mulheres brancas e mulheres negras”. Texto para Discussão, n. 769.

Zucchi, J.D.; Hoffmann, R. (2001). "Diferenças de renda associadas à cor: Brasil. Pesquisa e Debate, vol. 15 (1), p. 107-129.

Recebido em: 31 de agosto de 2012

Aceite em: 15 de fevereiro de 2013 